\title{
ANALISA PEMBELIAN KOPI DI DIALOGKOPI SUKOHARJO
}

\author{
Candra Nugroho, Bambang Mursito, Sudarwati \\ Fakultas Ekonomi, Universitas Islam Batik Surakarta \\ Email : candranug217@gmail.com
}

\begin{abstract}
This study aims to determine the effect of partial and simultaneous coffee purchases at the Dialogue in Sukoharjo. This type of research is quantitative research. The population in this study were 100 people in Dialogkopi Sukoharjo, while the sample used was 25. Then the data were analyzed using SPSS version 22, with quantitative analysis which included validity and reliability tests, classic assumption tests, multiple linear regression analysis, hypothesis testing with $F$ test and $t$ test and coefficient of determination. The $F$ test results indicate that product quality, price and location simultaneously and significantly influence purchasing decisions at Dialogkopi Sukoharjo. The results of the t test show that product quality has a positive and significant effect on purchasing decisions at Dialogkopi Sukoharjo, the value of having a positive and significant influence on purchasing decisions at Dialogkopi Sukoharjo and location has a positive and significant effect on purchasing decisions at Dialogkopi Sukoharjo. The coefficient of determination shows that the variables of product quality, price and location have an influence of $72.6 \%$ on the purchasing decision variable at Dialogkopi Sukoharjo
\end{abstract}

Keywords: Product quality, Price, Location, Purchase decision

\section{PENDAHULUAN}

Banyaknya bisnis yang mengandalkan teknologi untuk mencari ide dan memasarkan produknya. Oleh sebab itu sebagai seorang pebisnis yang berada pada era teknologi seperti saat ini dituntut untuk selalu kreatif dan inovatif dalam memunculkan ide-ide baru, termasuk dalam memasarkan produk yang dimiliki.

Kualitas Produk didefinisikan sebagai sesuatu yang dapat ditawarkan ke dalam pasar untuk diperhatikan, dimiliki, dipakai, atau dikonsumsi sehingga dapat memuaskan keinginan atau kebutuhan (Dinawan, 2010). Sedangkan kualitas produk adalah keadaan fisik, fungsi dan sifat suatu produk bersangkutan yang dapat memenuhi selera dan kebutuhan konsumen dengan memuaskan sesuai nilai uang yang telah dikeluarkan (Ranto, 2014

Harga merupakan salah satu variabel penting dalam pemasaran, dimana harga dapat mempengaruhi konsumen dalam mengambil keputusan untuk membeli suatu produk. Harga merupakan indikator kualitas dan karena itu dirancang sebagai salah satu instrumen penjualan sekaligus sebagai instrumen kompetisi yang menentukan (Dinawan, 2010).

Lokasi ialah tempat, kedudukan secara fisik yang mempunyai fungsi strategis karena dapat ikut menentukan tercapainya tujuan badan usaha (Sepang et al, 2014). Lokasi yang strategis akan membuat konsumen merasa puas dalam melakukan pembelian. Adanya lokasi yang strategis yang dekat dengan tempat tinggal, dekat dengan tempat melakukan aktivitas, akan membuat konsumen mudah menjangkau lokasi usaha dengan sedikit mengeluarka pengorbanan, baik tenaga maupun materi. (Nurseto et al 2010).

Keputusan pembelian adalah pemilihan dari dua atau lebih alternative pilihan keputusan pembelian, artinya bahwa seseorang dapat membuat keputusan, harus tersedia beberapa alternatif pilihan. Keputusan pembelian merupakan suatu tindakan yang dilakukan konsumen dikarenakan adanya dorongan-dorongan atau motif-motif yang dirasakan sehingga menimbulkan minat atau dorongan untuk memenuhi kebutuhan (Taroreh et al, 2015). 
Jika dilihat dari hal tersebut diatas, peneliti menyampaikan bahwa layak untuk melakukan penelitian mengenai (X1) kualitas produk, (X2) harga serta (X3) lokasi terhadap (Y)keputusan pembelian di Dialog Kopi Sukoharjo. Dan kemudian akan dituangkan dalam bentuk tulisan ilmiah yang berjudul Analisa Pembelian Kopi di DialogKopi Sukoharjo.

\section{LANDASAN TEORI}

\section{Keputusan Pembelian}

Keputusan pembelian merupakan suatu keputusan pelanggan yang dipengaruhi oleh, teknologi, ekonomi keuangan, produk, budaya, politik, promosi, lokasi, harga, physical evidence, process people dan people, sehingga membentuk suatu sikap pada pelanggan untuk mengolah semua informasi dan mengambil kesimpulan berupa response yang muncul apa yang akan dibeli

\section{Kualitas Produk}

Merupakan suatu karakteristik produk yang bisa memuaskan pelanggan sesuai dengan apa yang diharapan dari pelanggan akan produk tersebut

\section{Harga}

Adalah sejumlah nilai dalam bentuk uang termasuk barang ataupun jasa untuk mengambil alih hak milik suatu barang dan jasa kepada pihak lain

\section{Lokasi}

Merupakan tempat berdirinya perusahaan atau tempat usaha.

\section{METODE PENELITIAN}

Jenis penelitian yaitu penelitian kuantitatif. Tempat penelitian di Dialogkopi Sukoharjo. Waktu penelitian dilaksanakan kurang lebih selama 6 bulan dari bulan September 2018 sampai dengan bulan Februari 2019. Populasi dari penelitian ini adalah pelanggan Dialogkopi sejumlah 910 orang tiap bulannya. teknik sampling yang digunakan metode sample acak, sedangkan sampel adalah pelanggan Dialogkopi sebanyak 100. Analisis data dengan uji asumsi klasik, regresi linear berganda, dan uji hipotesis.

\section{HASIL DAN PEMBAHASAN}

\subsection{Analisis Data}

1) Uji asumsi klasik

a. Uji normalitas

Dari hasil pengujian menunjukkan signifikan $0,478>0,05$ pada taraf signifikan alpha $5 \%$, maka distribusi data normal,.

\section{b. Uji Multikolineritas}

Untuk menguji ada atau tidaknya multikolinieritas yaitu dengan menggunakan nilai Variance Inflation Factor (VIF). Hasil uji multikolinearitas sebagai berikut : 


\begin{tabular}{lll}
\hline \multicolumn{1}{c}{ Variabel } & \multicolumn{1}{c}{ Tolerance } & VIF \\
\hline Kualitas Produk $\left(\mathrm{X}_{1}\right)$ & 0,871 & 1,148 \\
Harga $\left(\mathrm{X}_{2}\right)$ & 0,867 & 1,154 \\
Lokasi $\left(\mathrm{X}_{3}\right)$ & 0,797 & 1,255 \\
\hline
\end{tabular}

c. Uji hetroskedastisitas

Uji heteroskedastisitas dalam penelitian ini menggunakan uji glesjer dengan melihat angka. Adapun hasilnya sebagai berikut:

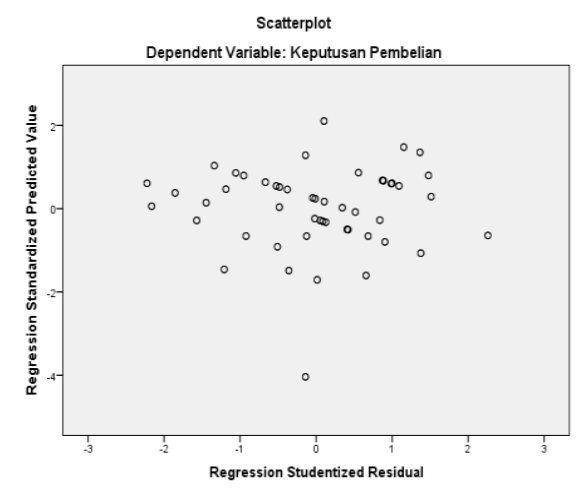

Berdasarkan hasil tersebut membuktikan bahwa titik-titik tersebut berada diatas dan dibawah nilai 0 . Hasil tersebut menunjukkan bahwa tidak terjadi adanya heteroskedastisitas.

2) Uji Regresi Linear berganda

Model persamaan regresi linier berganda yang dapat disusun adalah sebagai berikut:

$$
Y=\quad 1,623+0,331 X_{1}+0,259 X_{2}+0,274 X_{3}+e
$$

Nilai konstanta 1,623 artinya dengan tidak adanya variabel produk, harga, dan kualitas lokasi maka keputusan pembelian akan meningkat.

Nilai koefisien $b_{1}$ adalah sebesar 0,259 berarti variabel kualitas produk berpengaruh positif terhadap keputusan pembelian. Jika variabel kualitas produk meningkat maka keputusan pembelianjuga akan meningkat dan sebaliknya.

Nilai koefisien $b_{2}$ adalah sebesar 0,259 berarti variabel harga berpengaruh positif terhadap keputusan pembelian. Jika variabel harga meningkat maka keputusan pembelian juga akan meningkat dan sebaliknya.

Nilai koefisien $b_{3}$ adalah sebesar 0,274 berarti variabel Lokasi berpengaruh positif terhadap keputusan pembelian. Jika variabel Lokasi meningkat maka keputusan pembelian juga akan meningkat dan sebaliknya.

\section{3). Uji Hipotesis}

a. Uji F-simultan

$\left.\mathrm{F}_{\text {hitung }}>\mathrm{F}_{\text {tabel }} 88,646>2,76\right)$, maka/ Ho ditolak berarti ada pengaruh yang signifikan antara kualitas produk $\left(\mathrm{X}_{1}\right)$, harga $\left(\mathrm{X}_{2}\right)$, dan lokasi $\left(\mathrm{X}_{3}\right)$ secara bersama-sama terhadap keputusan pembelian (Y) dan dibuktikan dengan nilai sig $(0,000)$ lebih kecil dari dari $0,05(\alpha)$ 
maka kualitas produk $\left(\mathrm{X}_{1}\right)$, harga $\left(\mathrm{X}_{2}\right)$, dan lokasi $\left(\mathrm{X}_{3}\right)$ secara bersama-sama berpengaruh signifikan terhadap keputusan pembelian (Y).

b. Uji t-parsial

Uji t untuk menguji signifikan secara parsial pengaruh variabel independen yaitu kualitas produk, harga, lokasi terhadap variabel dependen yaitu keputusan pembelian. Ho ditolak t hitung lebih besar dari t tabel $(7,615>1,985)$ maka hal ini menunjukkan bahwa variabel kualitas produk mempunyai pengaruh yang signifikan terhadap keputusan pembelian dan terbukti nilai sig $(0,000)$ lebih kecil dari $0,05(\alpha)$ maka secara signifikan variabel kualitas produk berpengaruh secara signifikan terhadap keputusan pembelian.

c. Koefisien Determinasi $\mathrm{R}^{2}$

Hasil analisis data yang menggunakan bantuan komputer program SPSS for window maka dapat diperoleh Adjusted $\mathrm{R}$ square $\left(\mathrm{R}^{2}\right)$ sebesar 0,726, hal ini menunjukkan bahwa variabel kualitas produk $\left(\mathrm{X}_{1}\right)$, harga $\left(\mathrm{X}_{2}\right)$, dan lokasi $\left(\mathrm{X}_{3}\right)$ mempunyai kontribusi/sumbangan terhadap keputusan pembelian sebesar 72,6\%. Sedangkan sisanya $(100 \%-72,6 \%=27,4 \%)$ dipengaruhi oleh faktor-faktor lain diluar variabel yang diteliti yaitu selera, pendapatan, kemasan.

\subsection{Pembahasan}

1) Pengaruh kualitas produk, harga, dan lokasi berpengaruh secara simultan dan signifikan terhadap keputusan pembelian kopi di Dialog Kopi Sukoharjo

Diketahui $F_{\text {hitung }}>F_{\text {tabel }} 88,646>2,76$ ), maka Ho ditolak berarti ada pengaruh yang signifikan antara kualitas produk $\left(\mathrm{X}_{1}\right)$, harga $\left(\mathrm{X}_{2}\right)$, dan lokasi $\left(\mathrm{X}_{3}\right)$ secara bersama-sama terhadap keputusan pembelian $(\mathrm{Y})$ dan dibuktikan dengan nilai sig $(0,000)$ lebih kecil dari dari $0,05(\alpha)$ maka kualitas produk $\left(\mathrm{X}_{1}\right)$, harga $\left(\mathrm{X}_{2}\right)$, dan lokasi $\left(\mathrm{X}_{3}\right)$ secara bersama-sama berpengaruh signifikan terhadap keputusan pembelian (Y).

2) Hasil variabe kualitas produk mempunyai pengaruh yang signifikan terhadap keputusan pembelian dan terbukti nilai sig $(0,002)$ lebih kecil dari 0,05 $(\alpha)$ maka secara signifikan variabel kualitas produk berpengaruh secara signifikan terhadap keputusan pembelian.

3) Hasil variabel harga mempunyai pengaruh yang signifikan terhadap keputusan pembelian dan terbukti nilai sig $(0,013)$ lebih kecil dari $0,05(\alpha)$ maka secara signifikan variable harga berpengaruh secara signifikan terhadap keputusan pembelian

4) Hasil variabel lokasi mempunyai pengaruh yang signifikan terhadap keputusan pembelian dan terbukti nilai sig $(0,000)$ lebih kecil dari $0,05 \quad(\alpha)$ maka secara signifikan variabel berpengaruh secara signifikan terhadap keputusan pembelian.

5) Hasil analisis koefisien determinasi $\left(R^{2}\right)$ diperoleh Adjusted $R$ square $\left(R^{2}\right)$ sebesar 0,726 , hal ini menunjukkan bahwa variabel kualitas produk $\left(\mathrm{X}_{1}\right)$, harga $\left(\mathrm{X}_{2}\right)$, dan lokasi $\left(\mathrm{X}_{3}\right)$ mempunyai kontribusi/sumbangan terhadap keputusan pembeliansebesar 72,6\%. Sedangkan sisanya $(100 \%-72,6 \%=27,4 \%)$ dipengaruhi oleh faktor-faktor lain diluar variabel yang diteliti yaitu selera, pendapatan, kemasan. 


\section{KESIMPULAN DAN SARAN}

\subsection{Kesimpulan}

Dari hasil penelitian diketahui bahwa kualitas produk, harga, dan lokasi berpengaruh simultan dan signifikan pada keputusan pembelian di Dialogkopi Sukoharjo. Sedangkan secara parsial variabel kualitas produk, harga dan lokasi berpengaruh positif dan signifikan terhadap keputusan pembelian di Dialogkopi Sukoharjo

\subsection{Saran}

1) Bagi peneliti yang lain sebaiknya menambah variabel yang diteliti tidak hanya pada variabel kualitas produk, harga dan lokasi dalam mempengaruhi keputusan pembelian.

2) Bagi kedai Dialogkopi sebaiknya terus mempertahankan stabilitas harga agar konsumen tetap loyal.

3) Bagi kedai Dialogkopi meningkatkan kualitas produk agar konsumen tertarik dengan kualitas yang memiliki khas tersendiri.

4) Bagi kedai Dialogkopi lebih memperhatikan lokasi parkir bagi pembeli agar lebih nyaman dan aman.

\section{DAFTAR PUSTAKA}

Alma, B. 2011. Manajemen Pemasaran dan Pemasaran Jasa. Bandung: Alfabeta

Dinawan, Muhammad Rhendria. 2010. Jurnal Analisis Faktor - Faktor Yang Mempengaruhi Keputusan Pembelian. Jurnal Sains Pemasaran Indonesia Vol IX No.03 Hal 335 - 369

Durianto, Darmadi. 2014. Brand Equity Ten Strategi Memimpin Pasar. Jakarta: PT. Gramedia Pustaka Utama. Hal 78

Fure, Ferdyanto, Lapian, Joyce. Dan Taroreh, Rita. 2015. Jurnal Pengaruh Brand Image, Kualitas Poduk dan Harga Terhadap Keputusan Pembelian Konsumen Di J.CO Manado. Jurnal EMBA Vol.3 No.1 Hal.367-377

Ghozali, I. 2013. Aplikasi Analisis Multivariate dengan Program SPSS. Cetakan keempat. Semarang: Badan Penerbit Universitas Diponegoro

Hurriyati, Ratih. 2015. Bauran pemasaran dan loyalitas konsumen. Bandung: Alfabeta

Kodu, Sarini. 2013. Jurnal Harga, Kualitas Produk Dan Kualitas Pelayanan Pengaruhnya Terhadap Keputusan Pembelian Mobil Toyota Avanza. Jurnal EMBA Vol.1 No.3 Hal. 1251-1259

Kotler, P dan Armstrong,G. 2012. Prinsip-Prinsip Pemasaran. Jakarta: Erlangga

Ma’ruf, H. 2015. Pemasaran Ritel. Jakarta: PT. Gramedia Pustaka Utama

Pangenggar, Gadhang. Hidayat,Wahyu. \& Nurseto, Sendhang. 2010. Jurnal Pengaruh Kualitas Pelayanan, Lokasi, Dan Fasilitas Terhadap Keputusan Pembelian.

Peter, J. Paul dan Olson, Jerry C. 2014. Perilaku Konsumen dan Strategi Pemasaran. Edisi Sembilan. Buku 2. Jakarta: Penerbit Salemba Empat

Pride, W.M., and Ferrell. 2010. Marketing. Fiftinth Edition. Canada: South Western International Edition 
Ranto, Dwi Wahyu Pril. 2014. Jurnal Pengaruh Harga, Desain Produk, Kualitas Produk dan Citra Merek Terhadap Keputusan Pembelian Konsumen Pada Produk UKM Di Yogyakarta Vol. 5 No.02 Hal 206-218

Sarwono, J. 2011. Metode Riset Skripsi Pendekatan Kuantitatif. Jakarta: Media Elek Komputindo

Sugiono, 2013, Metode Penelitian Pendidikan : Pendekatan Kuantitatif, Kualitatif, dan $R \&$ \& , Bandung : Alfabeta.

Sugiyono. 2015. Metode Penelitian Kuantitatif, Kualitatif, dan R\&D. Bandung: Alfabeta.

Tjiptono, F. 2012. Strategi Bisnis Pemasaran. Yogyakarta: Andi Offset

Tjiptono, Fandy. 2010. Strategi pemasaran. Yogyakarta: ANDI. Hal.136

Walukow, Agnes Ligia Pratisitia. Mananeke, Lisbeth. Sepang, Jantje . 2014. Jurnal Pengaruh Kualitas Produk, Harga, Promosi Dan Lokasi Terhadap Keputusan Pembelian Konsumen Di Bentenan Center Sonder Minahasa. Jurnal EMBA Vol.2 No.3 Hal. 1737-1749

Sinambow Sandy, Trang Irvan. 2015. Jurnal Pengaruh Harga, Lokasi, Promosi Dan Kualitas Layanan Terhadap Keputusan Pembelian Pada Toko Komputer Game Zona Mega Mall Manado. Jurnal EMBA Vol.3 No.3 , Hal.300-311

Budiwati Hesti. Jurnal Implementasi Marketing Mix Dan Pengaruhnya Terhadap Keputusan Pembelian Konsumen Pada Produk Unggulan Keripik Pisang Agung Di Kabupaten Lumajang. Jurnal Wiga Vol. 2 No. 2 Hal 29-44

Lamidi., Avetoe Haja. 2015. Jurnal Pengaruh Harga, Kualitas Pelayanan Dan Lokasi Terhadap Keputusan Pembelian Konsumen. Jurnal Ekonomi dan Kewirausahaan Vol. 15 No. 3 Hal 367 - 373

Kurniawan Ferdy Zoel. 2013. Pengaruh Harga, Produk, Lokasi Dan Pelayanan Terhadap Keputusan Pembelian Pada Soto Angkring "Mas Boed” Spesial Ayam Kampung Semarang. 